\title{
Do we really understand the role of the prefrontal cortex in placebo analgesia?
}

Eleni Frangos*1, Nicholas Madian*1, Binquan Wang ${ }^{1}$, Megan L. Bradson ${ }^{1}$, John L. Gracely ${ }^{1}$,

Emily A. Richards ${ }^{1}$, Luana Colloca ${ }^{2,3}$, Petra Schweinhardt ${ }^{4,5}$, M. Catherine Bushnell ${ }^{1}$, Marta

Ceko $^{1,6}$

${ }^{1}$ National Center for Complementary and Integrative Health, National Institutes of Health,

Bethesda, MD, United States

${ }^{2}$ Department of Pain and Translational Symptom Science, School of Nursing, University of Maryland, Baltimore, MD, United States

${ }^{3}$ Department of Anesthesiology, School of Medicine, University of Maryland, Baltimore, MD, United States

${ }^{4}$ The Alan Edwards Centre for Research on Pain, Neurology and Neurosurgery, McGill

University, Montreal, QC, Canada

${ }^{5}$ Department of Chiropractic Medicine, Balgrist University Hospital and University of Zurich, Zurich, Switzerland

${ }^{6}$ Institute of Cognitive Science, University of Colorado, Boulder, CO, United States

${ }^{*}$ E. Frangos and N. Madian contributed equally to this article.

Corresponding author:

Eleni Frangos, $\mathrm{PhD}$

National Center for Complementary and Integrative Health

National Institutes of Health

10 Center Drive, Bldg 10 Rm 4-1730

Bethesda, MD 20892, United States

Tel.: 301-451-6710

E-mail address: eleni.frangos@nih.gov 


\section{ABSTRACT}

Several reviews have strongly implicated prefrontal cortical engagement in expectation-based placebo analgesia. We recently found a robust placebo analgesic response and associated decreases in pain-related cortical activations, without observable prefrontal engagement. We hypothesized our substantial conditioning and weak verbal instructions diminished expectationrelated prefrontal activation. To test this, we examined the same subjects during a conditioning procedure, in which expectancy of pain relief was high. In two conditioning sessions, noxious heat was applied to a leg region treated with an "analgesic" cream and another treated with a "moisturizing" cream. In reality, both creams were inert, but the temperature applied to the moisturizing-cream area was $2^{\circ} \mathrm{C}$ higher than that applied to the analgesic-cream area.

Functional MRI was acquired during the second conditioning session. Pain ratings were lower for the low heat than the high heat, with corresponding reduced activations in pain-related regions. Similar to previous studies with strong expectation for pain relief, we observed more prefrontal activations during the "analgesic" than the control condition. Nevertheless, contrary to the idea of active prefrontal engagement, the relative activation was based on differences in negative BOLD signals. A literature review revealed that only a few studies conclusively showed active engagement of prefrontal cortex, i.e. increased positive BOLD signal during high expectation compared to a control, with variable timing and spatial-specificity. We suggest that this variability is due to the heterogeneous influence of cognitive, emotional and motivational factors. Future studies should attempt to unravel the multiple contributions to placebo responsiveness in the prefrontal cortex. 
bioRxiv preprint doi: https://doi.org/10.1101/2021.06.18.449012; this version posted June 20, 2021. The copyright holder for this preprint

(which was not certified by peer review) is the author/funder. This article is a US Government work. It is not subject to copyright under 17 USC 105 and is also made available for use under a CCO license.

\section{INTRODUCTION}

Placebo analgesia induction procedures comprise distinct elements which appear to have separable neurobiological underpinnings. For example, the effects of expectation-enhancing verbal instructions (e.g., "this 'powerful analgesic' will decrease your pain") seem to be mediated by the opioid system, in that they can be blocked by naloxone [1], an opioid antagonist, and activate mu-opioid neurotransmission [51]. By contrast, the effects of associative learningrelated conditioning, in which stimulus intensities are surreptitiously manipulated during a conditioning phase, may be mediated by other systems, such as the cannabinoid system [6].

Similarly, different regions of the brain may be involved in placebo analgesia depending on the method of induction. Typically, placebo induction paradigms include both expectation-inducing verbal instructions and conditioning through associative learning. Increased activation in prefrontal regions, such as the dorsolateral prefrontal cortex (DLPFC), ventromedial prefrontal cortex (VMPFC), and the rostral anterior cingulate cortex ( $\mathrm{ACC}$ ), have been widely implicated in the placebo effect by studies using paradigms that combine expectation-enhancing verbal instructions and conditioning [3; 18; 45]. However, in our recent placebo analgesia study [15], none of these regions were found to be activated during the placebo test phase in a large sample of healthy participants, despite the presence of a robust behavioral placebo effect. Additionally, the placebo effect induced in this study was not blocked by naloxone. We hypothesized that the lack of prefrontal activation or naloxone effect was due to the fact that in addition to the standard instructions regarding the effectiveness of the "analgesic" (placebo) cream (e.g., "this cream is a highly effective topical pain reliever"), the participants were also given certain instructions not typically given in most placebo studies (i.e., that the naloxone could block the effect of the "analgesic" [placebo] cream), which may have reduced the participants' expectations of pain relief during the test phase. As a result, we proposed that the observed placebo effect was primarily driven by learning-related conditioning that did not activate opioidergic expectation-related prefrontal regions. 
bioRxiv preprint doi: https://doi.org/10.1101/2021.06.18.449012; this version posted June 20, 2021. The copyright holder for this preprint

(which was not certified by peer review) is the author/funder. This article is a US Government work. It is not subject to copyright under 17 USC 105 and is also made available for use under a CCO license.

Importantly, fMRI data was also collected during the conditioning phase, prior to the test phase and the administration of naloxone. During this period, participants' expectancy of pain relief should have been robust, as they had not yet been given the naloxone that they were told could block the effect of the "analgesic" (placebo) cream. Thus, the conditioning scan provided us with the opportunity to test our hypothesis, i.e., if the lack of prefrontal activation during the test phase was due to reduced expectancy caused by the drug administration, then prefrontal activations should be observed during the conditioning phase, prior to the drug administration, when expectancy of pain relief was high and reinforced by the conditioning trials. Here, we examined the anticipation and experience of pain relief during the conditioning scan in the same large sample of healthy participants studied in Frangos et al. [15] to determine whether regions of the prefrontal cortex (PFC) are engaged during high expectancy of pain relief.

\section{METHODS}

\section{Participants}

This study is part of a larger, previously published study that assessed placebo-induced analgesia in fibromyalgia patients compared to healthy controls [15]. The present study only includes 46 healthy participants (39 females, 7 males, mean age $\pm S D, 40 \pm 13$ years, range 1964 years). The inclusion and exclusion criteria for the parent study are detailed in Frangos et al. [15]. In brief, the exclusion criteria for healthy participants included smoking of $>10$ cigarettes/week, alcohol consumption of $>7$ drinks/week for women and $>14$ drinks/week for men, use of recreational drugs and opioid medication, consumption of any pain medication other than NSAIDs within the past month or for more than one month on a continual basis within the past 6 months, pregnancy or breastfeeding, allergies to skin creams and lotions, chronic pain conditions, major medical, neurological, or current psychiatric conditions, including severe depression and generalized anxiety disorder, and MRI contraindications.

The study received approval from the NIH Institutional Review Board (IRB), and written informed consent was obtained from all participants according to the Declaration of Helsinki. As 
bioRxiv preprint doi: https://doi.org/10.1101/2021.06.18.449012; this version posted June 20, 2021. The copyright holder for this preprint

(which was not certified by peer review) is the author/funder. This article is a US Government work. It is not subject to copyright under 17 USC 105 and is also made available for use under a CCO license.

per IRB guidelines, the consent form included a general statement about deception: "At some point during the study we will give you misleading information. After the study is finished and all participants have been tested, we will explain how the information was not true and why." No further details regarding deception were provided, and participants were not informed that the purpose of the study was to investigate placebo analgesia. Participants were compensated for completion of the study.

\section{Study design}

The data presented here were collected during the second placebo conditioning phase (conditioning scan) of a larger placebo analgesia study [15]. The study included three placebo manipulation sessions (two sessions on day 1 in a mock scanner, and one session on day 2 during fMRI) and followed a well-established paradigm that included both verbally-induced expectation and conditioning components in a between- and within-subjects design [10; 13; 48].

The experimental design of the parent study is described in detail previously [15]. Briefly, participants were told that we were testing the mechanisms of a new powerful topical analgesic cream (the placebo cream) in comparison to a "hydrating" (control) cream. In actuality, both creams were identical. Participants came for testing on two separate days. On the first day, the "analgesic" cream was applied to two regions of the left leg and a "hydrating" cream to another two regions. After determining individual heat pain threshold and tolerance with a contact thermode, a mildly painful "low heat" stimulus was applied to one of the two "analgesic" regions, and a moderately painful "high heat" stimulus was applied to one of the two "hydrating" regions, with a temperature difference of $\sim 2^{\circ} \mathrm{C}$. On the second day, during the second placebo manipulation (conditioning scan), the same conditioning procedure was undertaken in the MRI scanner. After the conditioning scan, participants rated how effective they thought the cream was $(0=$ not effective at all, $10=$ the most effective $)$ and their desire for pain relief during the stimulus presentation $(0=$ no desire for pain relief, $10=$ the most intense desire for pain relief 
imaginable). The placebo experimental scans subsequently followed and are detailed in

Frangos et al., 2020.

\section{Trial paradigm}

The paradigm during the conditioning scan (Fig. 1) consisted of a baseline period (jittered 8-12 seconds; black crosshair on white background), an anticipation period (7 seconds; grayscale picture of control cream or placebo "analgesic" cream), a heat pulse (8.5 seconds; grayscale picture of thermode), a second anticipation period and heat pulse, a post-stimulus rest period (4 seconds), and 2 rating periods ( 7 seconds each for pain intensity [ 0 = no sensation, $100=$ pain threshold, $200=$ intolerable pain $]$ and unpleasantness [-100 = extremely unpleasant, $0=$ neutral, $100=$ extremely pleasant]). Each heat pulse was presented on one of 2 pairs of treated $4 \times 4 \mathrm{~cm}$ regions of the lower left leg.

\section{Behavioral data analysis}

All behavioral measures were analyzed using 2-tailed paired t-tests or Wilcoxon signed-rank test for data that were not normally distributed based on the Shapiro-Wilk test. A significance level of $p<0.05$ was used in all analyses.

\section{fMRI data pre-processing and analysis}

Details of the fMRI acquisition and analysis methods are described in our previous publication [15]. In brief, each condition was modelled separately across trials (Fig. 1), i.e., the first anticipation period, first heat pulse, second anticipation period, second heat pulse and pain rating periods (intensity and unpleasantness combined) that occurred within a trial were each modelled as separate EVs for each condition (high heat [control cream] or low heat [placebo "analgesic" cream). For higher-level contrasts, voxel-wise thresholds were set to $z>3.1$. If no differences were observed, the voxel-wise threshold was lowered to $z>2.3$ to assess subtle effects and minimize false negatives (Type II error). All contrasts were cluster-corrected for multiple comparisons across the whole brain at $p<0.05$. 


\section{RESULTS}

All 46 healthy participants were included in the analysis. A summary of demographic information can be found in the parent study [15]. Results are presented as mean \pm SD.

Manipulation Check: Low heat produced less pain and less neural activation than high heat During the conditioning scan (second placebo manipulation), the high heat temperature administered on the "hydrating" (control) cream sites was $47^{\circ} \mathrm{C} \pm 1.7^{\circ} \mathrm{C}$, whereas the low heat temperature administered on the "analgesic" (placebo) cream sites was $44.6^{\circ} \mathrm{C} \pm 1.8^{\circ} \mathrm{C}$. As expected, the low heat condition was rated as less intense and unpleasant compared to high heat (intensity: high heat $151.7 \pm 28.3$, low heat $118.1 \pm 34.3$; unpleasantness: high heat $49.7 \pm$ 23.9 , low heat $20.5 \pm 26.6$; p`s $<0.001$ ). At the end of the conditioning scan, participants reported a moderate desire for pain relief $(5.7 \pm 3.1)$ and rated the "analgesic" (placebo) cream as moderately effective $(5.5 \pm 2.5)$.

The neural responses corroborated the perceptual responses as the low heat condition was associated with less activation in pain processing regions than the high heat condition. Although both high and low noxious heat stimuli produced activations within pain responsive regions (Table 1, left panel Fig. 2), the high heat produced significantly greater activation within regions that include the insula, secondary sensory cortices (SI and SII), and anterior cingulate cortex (ACC) $(z>3.1, p<0.05$, Table 1, right panel Fig. 2). The activation patterns and differences were consistently observed during both the first and second heat pulses.

Pain relief was associated with PFC activation resulting from a difference in negative BOLD signals

PFC activation during stimulation periods. In order to evaluate regions related to perceived pain relief, we examined regions that were activated more during low heat (when participants were 
bioRxiv preprint doi: https://doi.org/10.1101/2021.06.18.449012; this version posted June 20, 2021. The copyright holder for this preprint

(which was not certified by peer review) is the author/funder. This article is a US Government work. It is not subject to copyright under 17 USC 105 and is also made available for use under a CCO license.

feeling pain relief) than during high heat (no relief). Whereas high heat produced greater activations in pain-related regions as described above, during the first pulse, low heat produced greater activations in prefrontal regions, including DLPFC and VLPFC, as well as the lateral occipital cortex ( $z>3.1, p<0.05$; Table 1; Figure 3A). Similarly, greater activity in the lateral occipital cortex and frontal pole were observed in the low heat $>$ high heat contrast during the second pulse $(z>3.1, p<0.05$; Table 1; Figure 3B). Nevertheless, an examination of the parameter estimates (PEs, which provide BOLD signal directionality) extracted from the regions showing greater activation during low heat compared to high heat revealed that the observed differences between conditions during both the first and second stimulus pulses were based on differences in negative PE values, or deactivations, rather than positive PE values representative of activations above baseline (see graphs in Figure 3).

No PFC activation in anticipation periods. During the first and second heat pulse anticipation periods for both the high and low heat conditions compared to baseline, we found activations mainly within the visual cortex $(z>3.1, p<0.05$; left panel Fig. 4; Table 2), likely as a result of the visual cues presented during this period. Of particular interest was the low $>$ high heat contrast for each anticipation period, as this contrast would indicate whether previously reported prefrontal networks are being engaged during anticipation of pain-relief. We did not observe any significant differences in either the first or second low pain anticipation $>$ high pain anticipation contrasts, using a cluster forming threshold of $z>3.1$ and cluster correction of $p>0.05$. During anticipation of the second stimulus pulse, regions including the VLPFC and hippocampus were activated during anticipation of both high and low pain, but there was no difference between the conditions (Table 2, left panel Fig. 4). To examine more subtle effects and minimize false negatives, we decreased the cluster forming threshold to $z>2.3$, and here we observed only minimal visual cortex activation in anticipation of low pain compared to high pain during the second stimulus pulse (right panel Fig. 4). No differences were observed in the high pain anticipation > low pain anticipation contrasts for both pairs of stimuli (Table 2). 


\section{DISCUSSION}

Recently, we reported significant placebo analgesic responses associated with decreased painrelated cortical activations but failed to observe placebo-induced prefrontal activations [15]. We hypothesized that our paradigm, which involved substantial conditioning and weak verbal expectation instructions, reduced expectation-related prefrontal activation. Therefore, here, we examined the same healthy subjects during the conditioning session in which expectancy of pain relief was high, as expecations were not yet violated by the drug administration that would potentially block the effect of the "analgesic" (placebo) cream. As expected for a condition with less nociceptive input, the pain intensity and unpleasantness of the low heat were rated lower than the high heat and decreased activation was observed within pain responsive regions including insula, S2, S1, and ACC. Importantly, low heat pain compared to control high heat pain produced greater PFC activations, supporting our initial hypothesis and converging with the literature on expectation-induced placebo analgesia PFC responses. Since PFC effects were observed during the conditioning but not the placebo test phase [15], it is likely that the difference is due to lower expectancy during the test phase, suggesting that expectancy and conditioning effects may, indeed, have distinct neural pathways [6; 34].

\section{Engagement of the PFC during anticipation and experience of pain relief}

Studies have shown that transient inhibition [26] and degeneration [7] of the PFC can block placebo analgesia. These findings, together with observations of differential PFC activation during placebo and control conditions [3], have been interpreted to indicate that control of subcortical regions via prefrontal engagement is necessary for expectation-based placebo analgesia [5]. Nevertheless, scrutinizing our own findings revealed an unexpected result: PFC "activations" observed during pain relief (low pain > high pain) were, in actuality, differences in negative BOLD responses, which seemed to contradict the prevalent theories. Thus, we questioned whether placebo-related PFC activations in other studies on healthy participants were also based on differences in negative BOLD signals. Table 3 summarizes the findings 
bioRxiv preprint doi: https://doi.org/10.1101/2021.06.18.449012; this version posted June 20, 2021. The copyright holder for this preprint

(which was not certified by peer review) is the author/funder. This article is a US Government work. It is not subject to copyright under 17 USC 105 and is also made available for use under a CCO license.

from studies included in two meta-analyses [2; 3] and more recent studies. Surprisingly, only six of the seventeen studies report PE values indicating BOLD signal directionality, which varied widely between and within studies. Taken together, these studies do not consistently corroborate the prevalent idea that expectation-based placebo is a result of increased PFC activity.

PFC regions associated with placebo activity varied temporally and spatially across studies. Even the DLPFC and the rACC, the two regions in which placebo-related activity were most commonly observed, were identified only in seven $[9 ; 13 ; 24 ; 35 ; 42 ; 48 ; 50]$ and eight $[8 ; 9 ; 13$; $17 ; 22 ; 23 ; 32 ; 48]$ of the seventeen studies, respectively. Other implicated PFC regions included the medial PFC (mPFC; four studies [19; 24; 30; 50]), orbitofrontal cortex (OFC; four studies [19; 24; 32; 50]), and ventrolateral prefrontal cortex (VLPFC; three studies [9; 29; 42]), among others [25; 43]. In fact, there was no single region where placebo-related activity was reported in a majority of the studies reviewed, and the lack of a discernable pattern among PFC regions associated with placebo analgesia during expectation or stimulation (Fig. 5), indicated that placebo analgesia involves parts of the PFC in some way, but there is great heterogeneity in how the PFC is implicated.

\section{Potential sources of PFC variability}

The results of our study, in which the same subjects had differential PFC activation depending on the paradigm elements, support the conclusions of a recent meta-analysis by Zunhammer et al. [52]: that between-study variability in PFC activation corresponds to the heterogeneity of placebo induction paradigms. As an example, the divergent placebo effects in the pregenual rACC observed by Eippert et al. [13] and Geuter et al. [17] could be related to differences in expectations induced by their paradigms: Eippert et al. [13] administered saline or naloxone, whereas Geuter et al. [17] included two placebo efficacy conditions. However, differences in expectation are unlikely to be the only way design heterogeneity contributes to variability. 
bioRxiv preprint doi: https://doi.org/10.1101/2021.06.18.449012; this version posted June 20, 2021. The copyright holder for this preprint

(which was not certified by peer review) is the author/funder. This article is a US Government work. It is not subject to copyright under 17 USC 105 and is also made available for use under a CCO license.

Other possible contributing factors are mood and attention, both of which modulate pain perception via different cortical circuitry [44]. Zunhammer et al. [53] suggest that different emotional regulation strategies, e.g., reappraisal or mindfulness, may be involved in placebo analgesia with differing levels of PFC activity. Yet, emotional regulation strategies may be influenced by setting-related [40] and cultural factors [11], which may each contribute differentially to between-study variability. The VMPFC plays a role in regulating negative affect [14], specifically in the extinction of the fear response to anticipated painful stimuli [36]. Thus, paradigms that induce negative affect, e.g., fear of painful stimuli, but also those that are conducive to the extinction of that fear, may induce greater VMPFC involvement. Other PFC responses to fear conditioning include DLPFC activations, and OFC and VMPFC deactivations [16]. Additionally, periaqueductal gray (PAG) activation has been observed during fear conditioning and early fear extinction [28]. These fear-related patterns of activity may be particularly prominent in studies that showed placebo-related activation during the anticipation period, since conditioned stimuli are used as cues.

Although more closely associated with subcortical areas, appetitive conditioning also involves the PFC. Exposure to appetitive-conditioned stimuli activates the medial OFC $[21 ; 27]$, whereas inhibition of conditioning reinstatement activates the VMPFC [12]. As relief from pain is rewarding $[4 ; 31]$, it is not surprising that these brain regions are engaged during placebo analgesia, but PFC engagement may vary depending on the induction and test paradigms, particularly timing factors. For example, OFC activation is associated with the acquisition of appetitive conditioning, but not with early or late extinction, whereas rACC activation is associated with the early extinction of appetitive conditioning, but not acquisition or late extinction [27]. Consequently, the variability observed within these regions may reflect the extent, duration, and efficacy of the placebo conditioning. For instance, the present neural activity was observed during a second conditioning session, which may have been too late to observe OFC involvement. Importantly, the rACC activation frequently observed in placebo studies may partially reflect the effects of early extinction, as most studies examine the placebo 
bioRxiv preprint doi: https://doi.org/10.1101/2021.06.18.449012; this version posted June 20, 2021. The copyright holder for this preprint

(which was not certified by peer review) is the author/funder. This article is a US Government work. It is not subject to copyright under 17 USC 105 and is also made available for use under a CCO license.

test phase when the placebo and control stimuli are equalized. Moreover, previous reports of rACC--PAG coupling during placebo analgesia [8; 13; 32; 49] may not only be reflective of pain modulation but also the moment of simultaneous extinction of appetitive and fear conditioning. Appetitive conditioning-induced activations are also influenced by personality traits, e.g., neuroticism [21] and sensation-seeking [41], that are dopamine-associated and correlate positively with placebo responsiveness [37], suggesting an intrinsic relationship among appetitive conditioning, dopaminergic neurotransmission, personality, and the placebo effect.

With regard to the role of attentional processes in placebo analgesia, related DLPFC activation has been suggested to reflect the redirection of attention away from the stimulus or toward the stimulus to evaluate treatment efficacy [48]. Thus, one might expect DLPFC activity in any situation in which participants are induced to direct attention toward or away from a stimulus, which is likely to occur repeatedly during placebo studies. DLPFC activation or deactivation might also reflect the degree of engagement of attentional and task-related networks. When painful stimuli are presented during a cognitive task, activity in the dorsomedial DLPFC decreases, while activity in the ventrolateral DLPFC increases [38]. Presumably, this corresponds respectively to deactivation of the default mode network [39] and activation of the extrinsic mode network [20], a generalized network involved in allocating cognitive resources to sensory processing or task performance. Thus, the level of attentional engagement in the paradigm may determine whether, where, and in what direction DLPFC activity occurs. Similarly, distractors may engage executive functions such as inhibition and set shifting, producing variable DLPFC and VLPFC activity across studies [33; 46; 47].

\section{Study limitations and suggestions for future placebo analgesia studies}

In the present study, the psychological and cognitive variables described above were not measured and controlled for. These factors should be considered in future studies to obtain a clear understanding of the role of the PFC in placebo analgesia. Furthermore, clarity and standardization of instructions could improve the control of directed attention and expectation. 
Also, when considering the early and late stages of pain in placebo studies, we should be mindful of the early and late contributions of conditioning and extinction. Finally, consistent reporting of the control and placebo conditions versus baseline to understand BOLD signal directionality is critical for interpreting subsequent contrasts used to assess functionality.

In conclusion, our study confirms previous findings of PFC activity during pain relief, relative to a control condition, when expectancy of pain relief is strong. Nevertheless, the relative activation is based on differences in negative BOLD signals contrary to the prevalent theory that active engagement of PFC is the underlying mechanism for expectation-related placebo analgesia. Further, examination of the literature revealed that only a few studies show active PFCengagement during placebo analgesia, and the timing and spatial-specificity of activity varies widely likely due to uncontrolled psychological and cognitive factors. Therefore, to better understand the role of the PFC in placebo analgesia, future studies should control for various psychological and cognitive factors, and shift from asking is the PFC involved to when, how and which sub-regions are involved.

\section{Conflict of interest statement}

The authors have no conflicts of interest to declare.

\section{Acknowledgements}

This research was supported by the Intramural Research Program of the $\mathrm{NIH}$, National Center for Complementary and Integrative Health. The authors thank Brian Walitt, Nicole Godwin, Linda Ellison-Dejewski, Brenda Justement, Susan Goo, and Patrick Korb for subject recruitment and clinical support. 


\section{References}

[1] Amanzio M, Benedetti F. Neuropharmacological dissection of placebo analgesia: expectationactivated opioid systems versus conditioning-activated specific subsystems. J Neurosci 1999;19(1):484-494.

[2] Amanzio M, Benedetti F, Porro CA, Palermo S, Cauda F. Activation likelihood estimation metaanalysis of brain correlates of placebo analgesia in human experimental pain. Hum Brain Mapp 2013;34(3):738-752.

[3] Atlas LY, Wager TD. A meta-analysis of brain mechanisms of placebo analgesia: consistent findings and unanswered questions. Handb Exp Pharmacol 2014;225:37-69.

[4] Baliki MN, Geha PY, Fields HL, Apkarian AV. Predicting value of pain and analgesia: nucleus accumbens response to noxious stimuli changes in the presence of chronic pain. Neuron 2010;66(1):149-160.

[5] Benedetti F. No prefrontal control, no placebo response. Pain 2010;148(3):357-358.

[6] Benedetti F, Amanzio M, Rosato R, Blanchard C. Nonopioid placebo analgesia is mediated by CB1 cannabinoid receptors. Nat Med 2011;17(10):1228-1230.

[7] Benedetti F, Arduino C, Vighetti S, Asteggiano G, Tarenzi L, Rainero I. Pain reactivity in Alzheimer patients with different degrees of cognitive impairment and brain electrical activity deterioration. Pain 2004;111(1-2):22-29.

[8] Bingel U, Lorenz J, Schoell E, Weiller C, Buchel C. Mechanisms of placebo analgesia: rACC recruitment of a subcortical antinociceptive network. Pain 2006;120(1-2):8-15.

[9] Bingel U, Wanigasekera V, Wiech K, Ni Mhuircheartaigh R, Lee MC, Ploner M, Tracey I. The Effect of Treatment Expectation on Drug Efficacy: Imaging the Analgesic Benefit of the Opioid Remifentanil. Science Translational Medicine 2011;3:70ra14-70ra14.

[10] Colloca L, Benedetti F. How prior experience shapes placebo analgesia. Pain 2006;124(12):126-133.

[11] Davis E, Greenberger E, Charles S, Chen C, Zhao L, Dong Q. Emotion experience and regulation in China and the United States: how do culture and gender shape emotion responding? Int J Psychol 2012;47(3):230-239.

[12] Ebrahimi C, Koch SP, Pietrock C, Fydrich T, Heinz A, Schlagenhauf F. Opposing roles for amygdala and vmPFC in the return of appetitive conditioned responses in humans. Transl Psychiatry 2019;9(1):148.

[13] Eippert F, Bingel U, Schoell ED, Yacubian J, Klinger R, Lorenz J, Buchel C. Activation of the opioidergic descending pain control system underlies placebo analgesia. Neuron 2009;63(4):533-543.

[14] Etkin A, Egner T, Kalisch R. Emotional processing in anterior cingulate and medial prefrontal cortex. Trends Cogn Sci 2011;15(2):85-93. 
[15] Frangos E, Ceko M, Wang B, Richards EA, Gracely JL, Colloca L, Schweinhardt P, Bushnell MC. Neural effects of placebo analgesia in fibromyalgia patients and healthy individuals. Pain 2021;162(2):641-652.

[16] Fullana MA, Harrison BJ, Soriano-Mas C, Vervliet B, Cardoner N, Avila-Parcet A, Radua J. Neural signatures of human fear conditioning: an updated and extended meta-analysis of fMRI studies. Mol Psychiatry 2016;21(4):500-508.

[17] Geuter S, Eippert F, Hindi Attar C, Buchel C. Cortical and subcortical responses to high and low effective placebo treatments. Neuroimage 2013;67:227-236.

[18] Geuter S, Koban L, Wager TD. The Cognitive Neuroscience of Placebo Effects: Concepts, Predictions, and Physiology. Annu Rev Neurosci 2017;40:167-188.

[19] Gollub RL, Kirsch I, Maleki N, Wasan AD, Edwards RR, Tu Y, Kaptchuk TJ, Kong J. A Functional Neuroimaging Study of Expectancy Effects on Pain Response in Patients With Knee Osteoarthritis. J Pain 2018;19(5):515-527.

[20] Hugdahl K, Raichle ME, Mitra A, Specht K. On the existence of a generalized non-specific task-dependent network. Front Hum Neurosci 2015;9:430.

[21] Klucken T, Kruse O, Klein S, Kampa M, Tapia Leon I, Stark R. The relationship between neuroticism and appetitive conditioning. Neurobiol Learn Mem 2019;164:107068.

[22] Kong J, Gollub RL, Rosman IS, Webb JM, Vangel MG, Kirsch I, Kaptchuk TJ. Brain activity associated with expectancy-enhanced placebo analgesia as measured by functional magnetic resonance imaging. J Neurosci 2006;26(2):381-388.

[23] Kong J, Jensen K, Loiotile R, Cheetham A, Wey HY, Tan Y, Rosen B, Smoller JW, Kaptchuk TJ, Gollub RL. Functional connectivity of the frontoparietal network predicts cognitive modulation of pain. Pain 2013;154(3):459-467.

[24] Kong J, Kaptchuk TJ, Polich G, Kirsch I, Vangel M, Zyloney C, Rosen B, Gollub RL. An fMRI study on the interaction and dissociation between expectation of pain relief and acupuncture treatment. Neuroimage 2009;47(3):1066-1076.

[25] Koyama T, McHaffie JG, Laurienti PJ, Coghill RC. The subjective experience of pain: where expectations become reality. Proc Natl Acad Sci U S A 2005;102(36):12950-12955.

[26] Krummenacher P, Candia V, Folkers G, Schedlowski M, Schonbachler G. Prefrontal cortex modulates placebo analgesia. Pain 2010;148(3):368-374.

[27] Kruse O, Tapia Leon I, Stark R, Klucken T. Neural correlates of appetitive extinction in humans. Soc Cogn Affect Neurosci 2017;12(1):106-115.

[28] Lindner K, Neubert J, Pfannmoller J, Lotze M, Hamm AO, Wendt J. Fear-potentiated startle processing in humans: Parallel fMRI and orbicularis EMG assessment during cue conditioning and extinction. Int J Psychophysiol 2015;98(3 Pt 2):535-545. 
[29] Lu HC, Hsieh JC, Lu CL, Niddam DM, Wu YT, Yeh TC, Cheng CM, Chang FY, Lee SD. Neuronal correlates in the modulation of placebo analgesia in experimentally-induced esophageal pain: a 3T-fMRI study. Pain 2010;148(1):75-83.

[30] Lui F, Colloca L, Duzzi D, Anchisi D, Benedetti F, Porro CA. Neural bases of conditioned placebo analgesia. Pain 2010;151(3):816-824.

[31] Navratilova E, Porreca F. Reward and motivation in pain and pain relief. Nat Neurosci 2014;17(10):1304-1312.

[32] Petrovic P, Kalso E, Petersson KM, Ingvar M. Placebo and Opioid Analgesia-- Imaging a Shared Neuronal Network. Science 2002;295:1737-1740.

[33] Ridderinkhof KR, van den Wildenberg WP, Segalowitz SJ, Carter CS. Neurocognitive mechanisms of cognitive control: the role of prefrontal cortex in action selection, response inhibition, performance monitoring, and reward-based learning. Brain Cogn 2004;56(2):129-140.

[34] Schafer SM, Geuter S, Wager TD. Mechanisms of placebo analgesia: A dual-process model informed by insights from cross-species comparisons. Prog Neurobiol 2018;160:101-122.

[35] Schenk LA, Colloca L. The neural processes of acquiring placebo effects through observation. Neuroimage 2020;209:116510.

[36] Schiller D, Delgado MR. Overlapping neural systems mediating extinction, reversal and regulation of fear. Trends Cogn Sci 2010;14(6):268-276.

[37] Schweinhardt P, Seminowicz DA, Jaeger E, Duncan GH, Bushnell MC. The anatomy of the mesolimbic reward system: a link between personality and the placebo analgesic response. J Neurosci 2009;29(15):4882-4887.

[38] Seminowicz DA, Davis KD. Interactions of pain intensity and cognitive load: the brain stays on task. Cereb Cortex 2007;17(6):1412-1422.

[39] Seminowicz DA, Moayedi M. The Dorsolateral Prefrontal Cortex in Acute and Chronic Pain. J Pain 2017;18(9):1027-1035.

[40] Tang Y, Huang Y. Contextual factors influence the selection of specific and broad types of emotion regulation strategies. Br J Soc Psychol 2019;58(4):1008-1033.

[41] Tapia Leon I, Kruse O, Stark R, Klucken T. Relationship of sensation seeking with the neural correlates of appetitive conditioning. Soc Cogn Affect Neurosci 2019;14(7):769-775.

[42] Theysohn N, Schmid J, Icenhour A, Mewes C, Forsting M, Gizewski ER, Schedlowski M, Elsenbruch S, Benson S. Are there sex differences in placebo analgesia during visceral pain processing? A fMRI study in healthy subjects. Neurogastroenterol Motil 2014;26(12):1743-1753.

[43] van der Meulen M, Kamping S, Anton F. The role of cognitive reappraisal in placebo analgesia: an fMRI study. Soc Cogn Affect Neurosci 2017;12(7):1128-1137. 
[44] Villemure C, Bushnell MC. Mood influences supraspinal pain processing separately from attention. J Neurosci 2009;29(3):705-715.

[45] Wager TD, Atlas LY. The neuroscience of placebo effects: connecting context, learning and health. Nat Rev Neurosci 2015;16(7):403-418.

[46] Wager TD, Jonides J, Reading S. Neuroimaging studies of shifting attention: a meta-analysis. Neuroimage 2004;22(4):1679-1693.

[47] Wager TD, Jonides J, Smith EE, Nichols TE. Toward a taxonomy of attention shifting: Individual differences in fMRI during multiple shift types. Cognitive, Affective, \& Behavioral Neuroscience 2005;5(2):127-143.

[48] Wager TD, Rilling JK, Smith EE, Sokolik A, Casey KL, Davidson RJ, Kosslyn SM, Rose RM, Cohen JD. Placebo-induced changes in FMRI in the anticipation and experience of pain. Science 2004;303(5661):1162-1167.

[49] Wager TD, Scott DJ, Zubieta JK. Placebo effects on human mu-opioid activity during pain. Proc Natl Acad Sci U S A 2007;104(26):11056-11061.

[50] Watson A, El-Deredy W, lannetti GD, Lloyd D, Tracey I, Vogt BA, Nadeau V, Jones AK. Placebo conditioning and placebo analgesia modulate a common brain network during pain anticipation and perception. Pain 2009;145(1-2):24-30.

[51] Zubieta JK, Bueller JA, Jackson LR, Scott DJ, Xu Y, Koeppe RA, Nichols TE, Stohler CS. Placebo effects mediated by endogenous opioid activity on mu-opioid receptors. J Neurosci 2005;25(34):7754-7762.

[52] Zunhammer M, Bingel U, Wager TD, Placebo Imaging C. Placebo Effects on the Neurologic Pain Signature: A Meta-analysis of Individual Participant Functional Magnetic Resonance Imaging Data. JAMA Neurol 2018;75(11):1321-1330.

[53] Zunhammer M, Spisak T, Wager TD, Bingel U, Placebo Imaging C. Meta-analysis of neural systems underlying placebo analgesia from individual participant fMRI data. Nat Commun 2021;12(1):1391. 
Table 1. Whole-brain BOLD responses during the first and second heat stimulation periods.

\begin{tabular}{|c|c|c|c|c|c|c|}
\hline \multirow[t]{2}{*}{ Region } & \multirow[t]{2}{*}{ voxels } & \multicolumn{3}{|c|}{$\begin{array}{c}\text { MNI } \\
\text { coordinates }\end{array}$} & \multirow{2}{*}{$\begin{array}{c}\text { Peak } \\
\text { z-score }\end{array}$} & \multirow[t]{2}{*}{ p-value } \\
\hline & & $\mathbf{x}$ & $\mathbf{y}$ & $\mathbf{z}$ & & \\
\hline
\end{tabular}

First heat stimulation period

\section{Low pain > baseline}

Insula $\mathrm{R}$

SII R

Central Operculum R

Frontal Pole $\mathrm{R}$

Occipital Pole L

Occipital Pole R

Frontal Orbital Cortex L

Insula L

Paracingulate Gyrus R

Cerebellum $\mathrm{L}$

Central Operculum L

SII L

\section{High pain $>$ baseline}

Insula $\mathrm{R}$

SII $R$

Occipital Fusiform Gyrus

Insula L

SII L

Anterior Cingulate Gyrus

SI R

Cerebellum $\mathrm{L}$

\begin{tabular}{|c|c|c|c|c|c|}
\hline \multirow[t]{4}{*}{4007} & 34 & 22 & -6 & 7.00 & \multirow[t]{4}{*}{$<0.001$} \\
\hline & 58 & -20 & 18 & 5.26 & \\
\hline & 56 & 6 & 2 & 5.83 & \\
\hline & 40 & 40 & 0 & 4.87 & \\
\hline 3876 & -18 & -96 & 6 & 7.39 & $<0.001$ \\
\hline 3006 & 22 & -98 & 12 & 6.44 & $<0.001$ \\
\hline \multirow[t]{2}{*}{1120} & -30 & 22 & -8 & 6.06 & \multirow[t]{2}{*}{$<0.001$} \\
\hline & -30 & 22 & 0 & 5.75 & \\
\hline 541 & 6 & 24 & 40 & 5.71 & $<0.001$ \\
\hline 216 & -20 & -68 & -54 & 5.33 & 0.003 \\
\hline \multirow[t]{2}{*}{198} & -60 & -18 & 12 & 4.86 & \multirow[t]{2}{*}{0.005} \\
\hline & -56 & -30 & 16 & 3.86 & \\
\hline \multirow[t]{2}{*}{9487} & 38 & 16 & 2 & 8.40 & \multirow[t]{2}{*}{$<0.001$} \\
\hline & 60 & -20 & 18 & 8.35 & \\
\hline 8774 & 30 & -64 & -22 & 6.78 & $<0.001$ \\
\hline \multirow[t]{2}{*}{5633} & -40 & -2 & -10 & 7.83 & \multirow[t]{2}{*}{$<0.001$} \\
\hline & -60 & -24 & 16 & 6.39 & \\
\hline 5223 & 4 & 14 & 34 & 7.50 & $<0.001$ \\
\hline 680 & 18 & -38 & 68 & 6.89 & $<0.001$ \\
\hline 324 & -18 & -66 & -52 & 6.47 & $<0.001$ \\
\hline 240 & 34 & 50 & 24 & 4.67 & 0.002 \\
\hline 234 & -20 & -38 & 68 & 4.61 & 0.002 \\
\hline 181 & -38 & 42 & 28 & 4.70 & 0.010 \\
\hline 381 & -40 & 50 & -10 & 5.12 & $<0.001$ \\
\hline 366 & 38 & -66 & 42 & 4.71 & $<0.001$ \\
\hline \multirow[t]{2}{*}{189} & -54 & 24 & 18 & 4.32 & \multirow[t]{2}{*}{0.005} \\
\hline & -44 & 22 & 40 & 3.63 & \\
\hline 150 & 46 & 18 & 42 & 4.10 & 0.017 \\
\hline 129 & -26 & -66 & 48 & 4.14 & 0.034 \\
\hline \multirow[t]{4}{*}{9186} & 6 & 0 & 66 & 6.95 & \multirow[t]{4}{*}{$<0.001$} \\
\hline & 6 & 2 & 42 & 6.86 & \\
\hline & 20 & -36 & 66 & 6.32 & \\
\hline & -20 & -38 & 58 & 5.11 & \\
\hline \multirow[t]{2}{*}{8803} & 50 & 6 & -6 & 6.47 & \multirow[t]{2}{*}{$<0.001$} \\
\hline & 46 & 4 & -4 & 6.28 & \\
\hline
\end{tabular}

Frontal Pole R

SI L

Frontal Pole L

\section{Low pain > High pain}

Frontal Pole L

Lateral Occipital cortex $\mathrm{R}$

Inferior Frontal Gyrus (VLPFC) L

Middle Frontal Gyrus (DLPFC) L

Middle Frontal Gyrus (DLPFC) R

Lateral Occipital cortex L

\section{High pain > Low pain}

Juxtapositional Lobule (formerly SMA)

Anterior Cingulate Cortex

SI R

SI L

Planum Polar R

Insula R 
bioRxiv preprint doi: https://doi.org/10.1101/2021.06.18.449012; this version posted June 20,2021. The copyright holder for this preprint (which was not certified by peer review) is the author/funder. This article is a US Government work. It is not subject to copyright under 17 USC 105 and is also made available for use under a CCO license.

SII R

Central Opercular Cortex L

Planum Polar L

Insula L

SII L

Cerebellum R

Frontal Pole L

Precentral Gyrus R

Frontal Pole R

Lateral Occipital Cortex L

\begin{tabular}{cccccc} 
& 60 & -22 & 18 & 5.95 & \\
4723 & -58 & 0 & 2 & 7.03 & $<0.001$ \\
& -54 & -4 & -2 & 6.89 & \\
& -34 & 0 & 4 & 5.77 & \\
& -54 & -30 & 16 & 5.57 & \\
706 & 32 & -52 & -28 & 4.99 & $<0.001$ \\
361 & -30 & 50 & 18 & 5.02 & $<0.001$ \\
320 & 40 & -4 & 48 & 4.55 & $<0.001$ \\
238 & 32 & 48 & 24 & 4.91 & 0.001 \\
160 & -50 & -70 & 4 & 4.51 & 0.013 \\
\hline
\end{tabular}

\section{Second heat stimulation period}

\section{Low pain > baseline}

Insula $\mathrm{R}$

Central Opperculum R

Central Opperculum L

SII R

Insula L

SII L

Thalamus $\mathrm{R}$

Frontal Lobe $\mathrm{R}$

Occipital Pole L

Occipital Pole R

Paracingulate Gyrus

Anterior Cingulate Cortex L

Cerebellum L

Frontal Pole L

Cerebellum $\mathrm{R}$

High pain $>$ baseline

\section{Central Operculum R}

SII R

Paracingulate Gyrus

Anterior Cingulate Cortex

Planum Polar L

Occipital Pole L

Occipital Pole R

Insula R

Insula L

SII L

SI R

Cerebellum L

Thalamus $\mathrm{R}$

Cerebellum $\mathrm{R}$

Frontal Pole $\mathrm{R}$

$\begin{array}{cccccc}14740 & 44 & -2 & -6 & 6.96 & <0.001 \\ & 54 & 4 & 0 & 6.99 & \\ & -60 & -22 & 16 & 6.96 & \\ & 62 & -20 & 18 & 6.55 & \\ & -38 & 0 & 10 & 6.64 & \\ & -58 & -24 & 18 & 6.33 & \\ & 14 & -10 & 2 & 5.18 & \\ & 44 & 38 & 26 & 5.24 & \\ 11424 & -18 & -98 & 4 & 7.64 & <0.001 \\ & 38 & -88 & 8 & 7.44 & \\ 2798 & 0 & 12 & 42 & 6.50 & <0.001 \\ & -4 & 18 & 36 & 6.06 & \\ 532 & -22 & -66 & -58 & 5.80 & <0.001 \\ 363 & -50 & 38 & 12 & 4.61 & <0.001 \\ 305 & 22 & -68 & -50 & 5.03 & <0.001\end{array}$

37180

$\begin{array}{lll}50 & 0 & 0\end{array}$

8.74

$<0.001$

$\begin{array}{llll}54 & -22 & 18 & 7.86\end{array}$

$\begin{array}{llll}0 & 12 & 42 & 7.79\end{array}$

$\begin{array}{lll}2 & 10 & 42\end{array}$

7.77

$\begin{array}{lll}-52 & 0 & -4\end{array}$

7.65

$\begin{array}{lll}-20 & -96 & 4\end{array}$

7.00

$\begin{array}{lll}22 & -96 & 4\end{array}$

6.78

$\begin{array}{lll}36 & 4 & 6\end{array}$

7.46

$\begin{array}{lll}-40 & 2 & -8\end{array}$

6.70

$\begin{array}{lll}-60 & -26 & 14\end{array}$

6.81

$\begin{array}{lll}14 & -42 & 66\end{array}$

6.17

$\begin{array}{lll}-26 & -64 & -22\end{array}$

6.39

$\begin{array}{lll}12 & -10 & 6\end{array}$

4.77

379

$\begin{array}{lll}14 & -68 & -52\end{array}$

4.69

$<0.001$

340

$\begin{array}{lll}28 & 42 & 18\end{array}$

4.61 
bioRxiv preprint doi: https://doi.org/10.1101/2021.06.18.449012; this version posted June 20, 2021. The copyright holder for this preprint (which was not certified by peer review) is the author/funder. This article is a US Government work. It is not subject to copyright under 17 USC 105 and is also made available for use under a CCO license.

SI L

Frontal Pole L

\section{Low pain > High pain}

Lateral Occipital Cortex R

Frontal Pole R

Frontal Pole L

High pain > Low pain

Juxtapositional Lobule (formerly SMA) $R$

SI R

Anterior Cingulate Cortex $R$

Superior Frontal Gyrus $R$

Central Operculum L

Planum Polar L

Insula L

Heschl's Gyrus R

Insula R

SII R

Central Operculum R

SI L

(a) prefrontal cortex; somatosensory cortex; VLPFC, ventral lateral prefrontal cortex

$\begin{array}{cccccc}267 & -16 & -44 & -60 & 4.52 & <0.001 \\ 191 & -32 & 40 & 22 & 4.51 & 0.005 \\ & & & & & \\ 377 & 34 & -76 & 42 & 4.53 & <0.001 \\ 363 & 44 & 36 & 10 & 4.83 & <0.001 \\ 121 & -42 & 48 & -6 & 4.29 & 0.024\end{array}$

$\begin{array}{llllll}2946 & 4 & -2 & 52 & 5.46 & <0.001\end{array}$

$\begin{array}{llll}14 & -30 & 68 & 5.41\end{array}$

$\begin{array}{llll}6 & 4 & 38 & 5.17\end{array}$

$\begin{array}{llll}20 & -8 & 64 & 4.85\end{array}$

$\begin{array}{llllll}267 & -52 & -12 & 8 & 4.35 & <0.001\end{array}$

$\begin{array}{llll}-50 & 0 & -2 & 4.27\end{array}$

$\begin{array}{llll}-34 & 6 & 6 & 3.61\end{array}$

$\begin{array}{llllll}258 & 40 & -20 & 4 & 4.04 & <0.001\end{array}$

$\begin{array}{llll}36 & -18 & 16 & 3.87\end{array}$

$\begin{array}{llll}54 & -22 & 18 & 3.66\end{array}$

$\begin{array}{llllll}219 & 52 & 0 & 4 & 4.89 & <0.001\end{array}$

$\begin{array}{llllll}160 & -22 & -36 & 62 & 4.39 & 0.006\end{array}$ 
bioRxiv preprint doi: https://doi.org/10.1101/2021.06.18.449012; this version posted June 20, 2021. The copyright holder for this preprint (which was not certified by peer review) is the author/funder. This article is a US Government work. It is not subject to copyright under 17 USC 105 and is also made available for use under a CCO license.

Table 2. Whole-brain BOLD responses during the first and second anticipation periods.

\begin{tabular}{|c|c|c|c|c|c|c|}
\hline \multirow{2}{*}{ Region } & \multirow{2}{*}{ voxels } & \multicolumn{3}{|c|}{ MNI coordinates } & \multirow{2}{*}{$\begin{array}{c}\text { Peak } \\
\text { z-score }\end{array}$} & \multirow{2}{*}{ p-value } \\
\hline & & $\mathbf{x}$ & $\mathbf{y}$ & $\mathbf{z}$ & & \\
\hline \multicolumn{7}{|l|}{ First anticipation period } \\
\hline \multicolumn{7}{|l|}{ Low pain > baseline } \\
\hline Occipital Pole L & 13641 & -16 & -98 & -2 & 9.14 & $<0.001$ \\
\hline Occipital Pole R & & 20 & -90 & -8 & 8.46 & \\
\hline Lateral Occipital Cortex L & 168 & -22 & -64 & 44 & 4.22 & 0.006 \\
\hline \multicolumn{7}{|l|}{ High pain > baseline } \\
\hline Occipital Fusiform Gyrus R & 13701 & 18 & -90 & -10 & 8.69 & $<0.001$ \\
\hline Occipital Pole & & -16 & -100 & 0 & 8.54 & \\
\hline \multicolumn{7}{|l|}{ Low pain > High pain } \\
\hline- & - & - & - & - & - & - \\
\hline \multicolumn{7}{|l|}{ High pain > Low pain } \\
\hline- & - & - & - & - & - & - \\
\hline \multicolumn{7}{|l|}{ Second anticipation period } \\
\hline \multicolumn{7}{|l|}{ Low pain $>$ baseline } \\
\hline Occipital Pole L & 20986 & -16 & -100 & 0 & 10.10 & $<0.001$ \\
\hline Lateral Occipital Cortex R & & 32 & -86 & -12 & 9.17 & \\
\hline Inferior Frontal Gyrus (VLPFC) L & 1186 & -40 & 14 & 18 & 5.24 & $<0.001$ \\
\hline Precentral Gyrus L & & -46 & -2 & 36 & 4.97 & \\
\hline Inferior Frontal Gyrus (VLPFC) R & 438 & 48 & 14 & 26 & 4.63 & $<0.001$ \\
\hline Hippocampus L & 145 & -22 & -28 & -8 & 6.33 & 0.008 \\
\hline Supramarginal Gyrus R & 130 & 68 & -20 & 18 & 3.93 & 0.014 \\
\hline Hippocampus R & 108 & 22 & -28 & -8 & 6.13 & 0.034 \\
\hline \multicolumn{7}{|l|}{ High pain > baseline } \\
\hline Occipital Pole R & 22333 & 12 & -90 & -8 & 8.81 & $<0.001$ \\
\hline Occipital Pole L & & -16 & -98 & 0 & 8.56 & \\
\hline Cerebellum R & & 22 & -66 & -48 & 5.24 & \\
\hline S2 L & & -60 & -24 & 18 & 4.63 & \\
\hline $\mathrm{S} 1 \mathrm{R}$ & & 16 & -42 & 66 & 4.49 & \\
\hline Hippocampus R & & 36 & -26 & -10 & 3.80 & \\
\hline Hippocampus L & & -22 & -32 & -4 & 5.24 & \\
\hline Precentral Gyrus L & 1470 & -54 & 0 & 42 & 5.49 & $<0.001$ \\
\hline Inferior Frontal Gyrus L (VLPFC) L & & -42 & 8 & 22 & 5.46 & \\
\hline $\mathrm{S} 1 \mathrm{R}$ & 927 & 62 & -18 & 28 & 5.00 & $<0.001$ \\
\hline Planum Temporale $\mathrm{R}$ & & 64 & -18 & 12 & 5.00 & \\
\hline Planum Polar R & & 48 & -4 & -2 & 4.42 & \\
\hline Insula R & & 40 & 0 & -14 & 4.23 & \\
\hline S2 R & & 36 & -30 & 22 & 4.11 & \\
\hline Cerebellum L & 161 & -22 & -68 & -52 & 4.66 & 0.005 \\
\hline \multicolumn{7}{|l|}{ Low pain > High pain } \\
\hline${ }^{*}$ Occipital Pole R & 312 & 32 & -96 & 4 & 4.71 & $<0.001$ \\
\hline${ }^{*}$ Occipital Pole L & 132 & -16 & -102 & 0 & 4.14 & $<0.001$ \\
\hline \multicolumn{7}{|l|}{ High pain > Low pain } \\
\hline- & - & - & - & - & - & - \\
\hline
\end{tabular}


bioRxiv preprint doi: https://doi.org/10.1101/2021.06.18.449012; this version posted June 20, 2021. The copyright holder for this preprint (which was not certified by peer review) is the author/funder. This article is a US Government work. It is not subject to copyright under 17 USC 105 and is also made available for use under a CCO license.

*, observed only in the analysis using cluster forming and cluster correction thresholds of $z>2.3$ and $p<$ 0.05 .

$\mathrm{L}$, left; R, right; VLPFC, ventral lateral prefrontal cortex 
bioRxiv preprint doi: https://doi.org/10.1101/2021.06.18.449012; this version posted June 20, 2021. The copyright holder for this preprint (which was not certified by peer review) is the author/funder. This article is a US Government work. It is not subject to copyright under 17 USC 105 and is also made available for use under a CCO license.

Table 3. Frontal cortex activity during placebo analgesia expectation or stimulation periods in studies reporting on healthy participants.

\begin{tabular}{|c|c|c|c|c|c|}
\hline Study & Conditioning & $\begin{array}{l}\text { Expectation } \\
\text { (E), } \\
\text { Stimulation } \\
\text { (S) }\end{array}$ & Region & $\begin{array}{l}\text { MNI } \\
\text { coordinates } \\
(x, y, z)\end{array}$ & $\begin{array}{l}\text { Parameter } \\
\text { estimates } \\
\text { reported? }\end{array}$ \\
\hline Petrovic et al., 2002† & $\begin{array}{l}\text { No description of } \\
\text { conditioning }\end{array}$ & $\begin{array}{l}S \\
S \\
S \\
S\end{array}$ & $\begin{array}{l}\text { rACC } \\
\text { OFC } \\
\text { OFC } \\
\text { OFC }\end{array}$ & $\begin{array}{l}19,34,14 \\
3134-10 \\
3151-17 \\
-2448-18\end{array}$ & $\mathrm{n} / \mathrm{a}$ \\
\hline $\begin{array}{l}\text { Wager et al., } 2004 \\
\text { (study 2)* }\end{array}$ & $\begin{array}{l}\text { Same day, } \\
6 \text { high, } 6 \text { low }\end{array}$ & $\begin{array}{l}\text { Early: } \\
\text { E } \\
\text { E } \\
\text { E } \\
\text { Late: } \\
\text { E } \\
\text { E }\end{array}$ & $\begin{array}{l}\text { DLPFC } \\
\text { DLPFC } \\
\text { dACC } \\
\text { rACC } \\
\text { dACC }\end{array}$ & $\begin{array}{l}42,4,30 \\
-42,14,30 \\
-16,-22,12 \\
\\
10,16,20 \\
-20,-20,24\end{array}$ & $\begin{array}{l}\text { No } \\
\text { No } \\
\text { No } \\
\text { No } \\
\text { No }\end{array}$ \\
\hline Koyama et al., 2005 & $\begin{array}{l}\text { Training day } w / \text { cues for } \\
\text { different temps. On scan day, } \\
33 \% \text { of trials falsely cued. }\end{array}$ & $\mathrm{E}$ & VmPFC & $-6,50,4$ & No \\
\hline Bingel et al., 2006 & $\begin{array}{l}2 \text { series of } 4 \text { stimuli, just } \\
\text { before scan. }\end{array}$ & $\mathrm{S}$ & rACC & $3,42,-18$ & $\begin{array}{l}\text { Yes (both } p \\
\text { and } n \text { ) }\end{array}$ \\
\hline Kong et al., 2006 & $\begin{array}{l}\text { Training day, } 6 \text { high/ } 6 \text { low; } \\
\text { test day, } 2 \text { high/ } 2 \text { low before } \\
\text { test. }\end{array}$ & $S$ & rACC & $2,44,10$ & No \\
\hline Eippert et al., 2009 & $\begin{array}{l}\text { Training day \& test day } \\
\text { manipulations } \\
6 \text { high, } 6 \text { low }\end{array}$ & $\begin{array}{l}\mathrm{S} \\
\mathrm{S}\end{array}$ & $\begin{array}{l}\text { DLPFC } \\
\text { rACC }\end{array}$ & $\begin{array}{l}22,12,38 \\
16,36,-12\end{array}$ & $\begin{array}{l}\text { Yes (both } p \\
\text { and } n \text { ) }\end{array}$ \\
\hline Kong et al., 2009 & $\begin{array}{l}\text { Same as Kong } 2006 \text { (training } \\
\text { \& test day conditioning) }\end{array}$ & $\begin{array}{l}\mathrm{S} \\
\mathrm{S} \\
\mathrm{S} \\
\mathrm{S} \\
\mathrm{S}\end{array}$ & $\begin{array}{l}\mathrm{mPFC} \\
\mathrm{mPFC} \\
\mathrm{mPFC} / \mathrm{rACC} \\
\text { OPFC } \\
\text { DLPFC }\end{array}$ & $\begin{array}{l}12,30,52 \\
-6,34,54 \\
-12,54,16 \\
-50,28,-14 \\
-62,6,18 \\
\end{array}$ & $\begin{array}{l}\text { No } \\
\text { No } \\
\text { No } \\
\text { No } \\
\text { No }\end{array}$ \\
\hline Watson et al., 2009 & $\begin{array}{l}\text { Training day } 1 \text { week before } \\
\text { testing; } 15 \text { high \& low laser } \\
\text { stimuli }\end{array}$ & $\begin{array}{l}E \\
E \\
E \\
E\end{array}$ & $\begin{array}{l}\text { MFC } \\
\text { DLPFC } \\
\text { OFC } \\
\text { aMCC }\end{array}$ & $\begin{array}{l}-6,44,34 \\
-24,52,18 \\
-10,40,-12 \\
-6,32,24 \\
\end{array}$ & $\begin{array}{l}\text { No } \\
\text { No } \\
\text { No } \\
\text { No }\end{array}$ \\
\hline Lu et al., $2010^{\dagger}$ & $\begin{array}{l}\text { Espophogeal distension. } \\
\text { Training day conditioning; } \\
\text { one low, one high distension }\end{array}$ & $\mathrm{E}$ & VLPFC & $-35,42,2$ & No \\
\hline Lui et al., 2010 & $\begin{array}{l}2 \text { conditioning runs on test } \\
\text { day. Laser, } 6 \text { high, } 6 \text { low on } \\
\text { each run. Scanned during } \\
\text { conditioning }\end{array}$ & $\begin{array}{l}E \\
E \\
E \\
E \\
S \\
S \\
S\end{array}$ & $\begin{array}{l}\text { MFG/IFG } \\
\text { MFG/SFG } \\
\mathrm{mPFC} / \mathrm{CG} \\
\mathrm{IFG} \\
\mathrm{MFG} / \mathrm{IFG} \\
\mathrm{mPFC} / \mathrm{SFG} \\
\mathrm{SFG} / \mathrm{MFG}\end{array}$ & $\begin{array}{l}44,30,26 \\
34,58,8 \\
6,26,38 \\
32,24,-14 \\
52,20,34 \\
6,54,16 \\
30,54,-2\end{array}$ & $\begin{array}{l}\text { No } \\
\text { No } \\
\text { No } \\
\text { No } \\
\text { No } \\
\text { No } \\
\text { No }\end{array}$ \\
\hline Bingel et al., 2011 & $\begin{array}{l}\text { Training day, } 10 \text { low temps } \\
\text { during remifentanil, } 10 \text { high } \\
\text { post-remi. }\end{array}$ & $\begin{array}{l}\mathrm{S} \\
\mathrm{S} \\
\mathrm{S} \\
\mathrm{S}\end{array}$ & $\begin{array}{l}\text { DLPFC } \\
\text { VLPFC } \\
\text { rACC } \\
\text { SgACC }\end{array}$ & $\begin{array}{l}38,22,38 \\
40,34,22 \\
-16,38,12 \\
6,16,-14\end{array}$ & $\begin{array}{l}\text { Yes but } \\
\text { non- } \\
\text { specific }\end{array}$ \\
\hline Geuter et al., 2013 & $\begin{array}{l}2 \text { training/test days (weak \& } \\
\text { strong placebo) Conditioning }\end{array}$ & $\begin{array}{l}\mathrm{E} \\
\mathrm{S}\end{array}$ & $\begin{array}{l}\text { rACC (pregenual) } \\
\text { rACC (subgenual) }\end{array}$ & $\begin{array}{l}8,36,14 \\
-36,20,0\end{array}$ & $\begin{array}{l}\text { Yes (both } p \\
\text { and } n \text { ) }\end{array}$ \\
\hline
\end{tabular}


bioRxiv preprint doi: https://doi.org/10.1101/2021.06.18.449012; this version posted June 20, 2021. The copyright holder for this preprint (which was not certified by peer review) is the author/funder. This article is a US Government work. It is not subject to copyright under 17 USC 105 and is also made available for use under a CCO license.

\begin{tabular}{|c|c|c|c|c|c|}
\hline & $\begin{array}{l}\text { (6 high/6 low) in exam room, } \\
\text { then in MRI. }\end{array}$ & & & & \\
\hline Kong et al., 2013 & $\begin{array}{l}\text { Thermal, contextual learning } \\
\& \text { conditioning scan w/cues } \\
\text { for high or low pain. Test scan } \\
\text { gave false cues. }\end{array}$ & $\begin{array}{l}E \\
E \\
E \\
S \\
S \\
S \\
S \\
S\end{array}$ & $\begin{array}{l}\text { rACC } \\
\text { MFG } \\
\text { IFG } \\
\text { rACC } \\
\text { aPFC } \\
\text { pPFC } \\
\text { MFG } \\
\text { IFG }\end{array}$ & $\begin{array}{l}12,40,10 \\
-20,24,50 \\
-24,64,18 \\
10,46,10 \\
-4,36,54 \\
-2,58,20 \\
-20,60,8 \\
-44,38,-10\end{array}$ & $\begin{array}{l}\text { No } \\
\text { No } \\
\text { No } \\
\text { No } \\
\text { No } \\
\text { No } \\
\text { No } \\
\text { No }\end{array}$ \\
\hline $\begin{array}{l}\text { Theysohn et al., } \\
2014^{* *}\end{array}$ & $\begin{array}{l}\text { Only Verbal instructions; No } \\
\text { conditioning }\end{array}$ & $\begin{array}{l}E \\
E \\
S \\
S\end{array}$ & $\begin{array}{l}\text { VLPFC } \\
\text { DLPFC } \\
\text { DLPFC } \\
\text { ACC }\end{array}$ & $\begin{array}{l}65,18,4 \\
48,16,18 \\
26,40,20 \\
10,12,28\end{array}$ & $\begin{array}{l}\text { No } \\
\text { Yes ( } n \text { vs } n \text { ) } \\
\text { No } \\
\text { No }\end{array}$ \\
\hline $\begin{array}{l}\text { Van der Meulen et } \\
\text { al., } 2017\end{array}$ & $\begin{array}{l}\text { Bingel conditioning on test } \\
\text { day only }\end{array}$ & $\begin{array}{l}\mathrm{E} \\
\mathrm{E}\end{array}$ & $\begin{array}{l}\text { MCC } \\
\text { MFG/SMA }\end{array}$ & $\begin{array}{l}-6,-28,46 \\
-10,-12,60\end{array}$ & $\begin{array}{l}\text { No } \\
\text { No }\end{array}$ \\
\hline Gollub et al., 2018 & $\begin{array}{l}\text { Same as Kong } 2006 \text { (training } \\
\text { \& test day conditioning) }\end{array}$ & $\begin{array}{l}\mathrm{S} \\
\mathrm{S}\end{array}$ & $\begin{array}{l}\text { OPFC } \\
\mathrm{SgACC} / \mathrm{mPFC}\end{array}$ & $\begin{array}{l}-36,46,-12 \\
2,44,-16 \\
\end{array}$ & $\begin{array}{l}\text { No } \\
\text { No }\end{array}$ \\
\hline Schenk et al., 2020 & $\begin{array}{l}\text { Observed videoclips of pain } \& \\
\text { analgesia faces (on test day) }\end{array}$ & $\mathrm{S}$ & DLPFC & $42,30,32$ & Yes ( $p$ vs $p)$ \\
\hline
\end{tabular}

*Findings presented in the table pertain to only the female population. No prefrontal activations during placebo conditions were observed in men.

**Wager 2004 study 1: Regions correlating with behavioral placebo effects (pain ratings, control - placebo) in the placebo > control neural contrast were the bilateral OFC, rACC, dACC, and bilateral DLPFC.

tCoordinates originally reported in Tailarach space but reported in MNI 152 T1 2mm space within the table.

aMCC, anterior mid-cingulate cortex; aPFC, anterior prefrontal cortex; CG, cingulate gyrus; dACC, dorsal anterior cingulate cortex; DLPFC, dorsal lateral prefrontal cortex; IFG, inferior frontal gyrus; MCC, midcingulate cortex; MFC, medial frontal cortex; MFG, middle frontal gyrus; MPFC, medial prefrontal cortex; $n$, negative; $n / a$, not applicable; OFC, orbital frontal cortex; OPFC, orbital prefrontal cortex; $p$, positive; PPFC, posterior prefrontal cortex; $r A C C$, rostral anterior cingulate cortex; SFG, superior frontal gyrus; SgACC, subgenual anterior cingulate cortex; SMA, supplementary motor area; VLPFC, ventral lateral prefrontal cortex; vmPFC, ventral medial prefrontal cortex. 


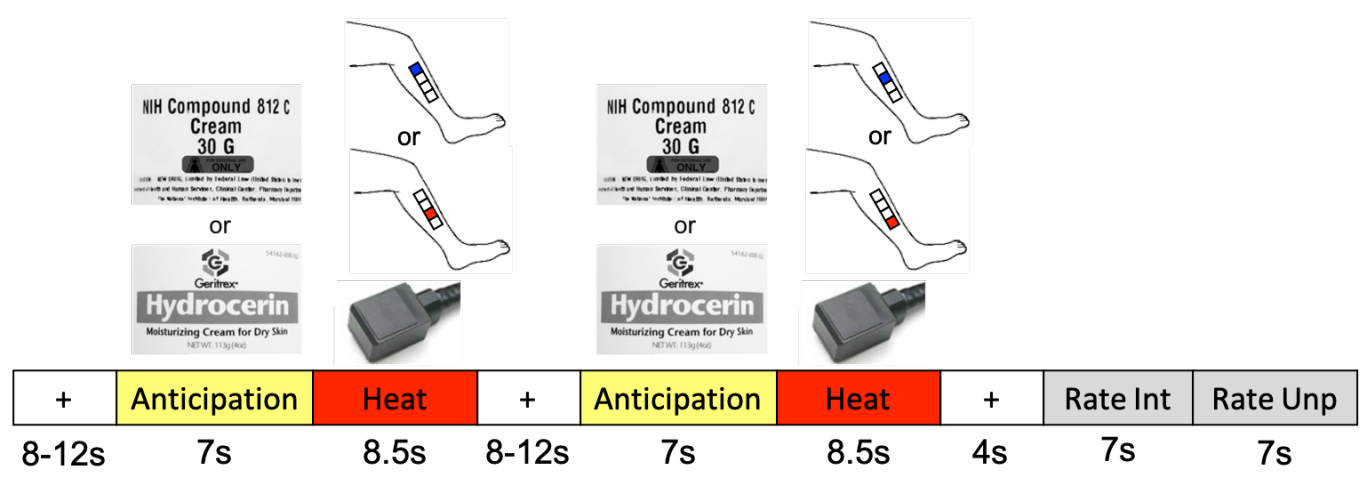

Figure 1. Experimental paradigm. The trial paradigm during the manipulation session consisted of a jittered interstimulus interval (ISI) of a black crosshair on white background, an anticipation period preceding the heat pulse (cue of either the "analgesic" (placebo) cream label (top image) or the "hydrating" (control) cream label (bottom image)), a low heat pulse (matched with the placebo cue) or a high heat pulse (matched with the control cue) on the left leg during which a thermode image was shown, a second jittered ISI, a second anticipation cue and matched heat pulse, a post-stimulus ISI, and a rating scale for pain intensity and pain unpleasantness. The blue and red squares on the leg images each indicate one of 2 pairs of $4 \times 4 \mathrm{~cm}$ regions where the heat pulses were applied. Adapted from Frangos et al., 2021. 


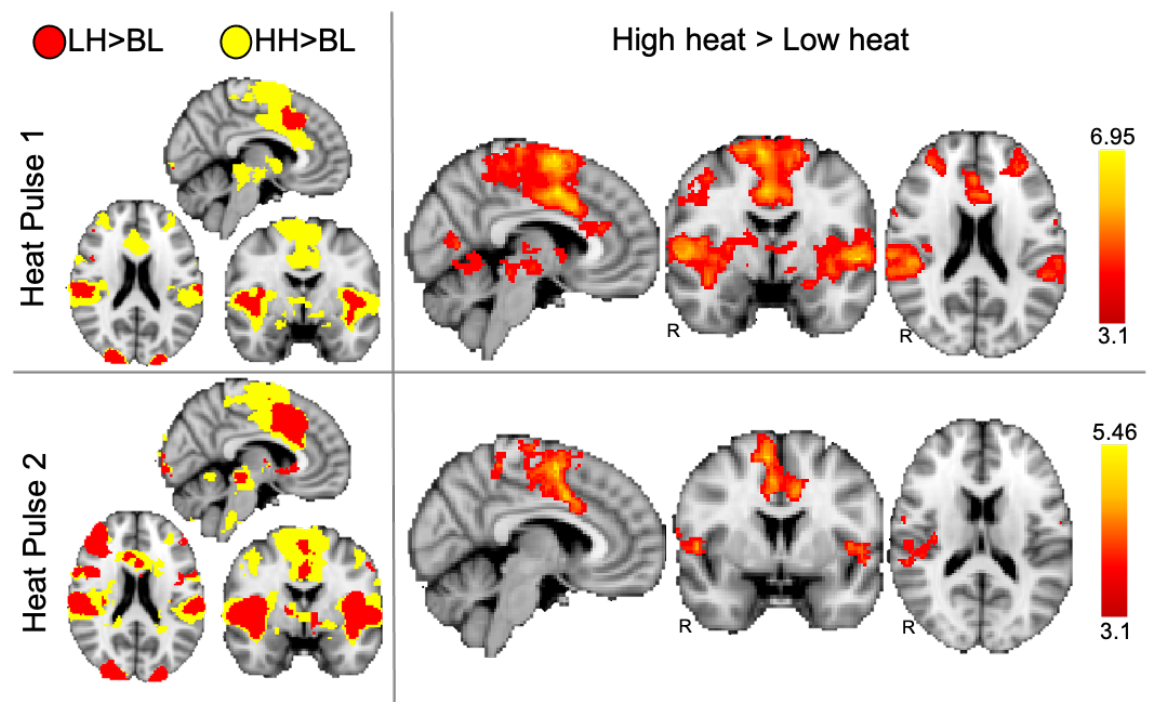

Figure 2. Neural responses to high and low painful heat. The left panel shows the pain-related activations in response to the low heat stimulus (red) and high heat stimulus (yellow) for each heat pulse. The right panel shows the difference in pain-evoked activations between the high and low heat stimuli for each heat pulse. All results are presented a voxel-based threshold of $z>$ 3.1, cluster correction of $\mathrm{p}<0.05$. BL, baseline; $\mathrm{HH}$, high heat; $\mathrm{LH}$, low heat; $\mathrm{R}$, right. 
A. Pulse 1 Low heat $>$ High heat
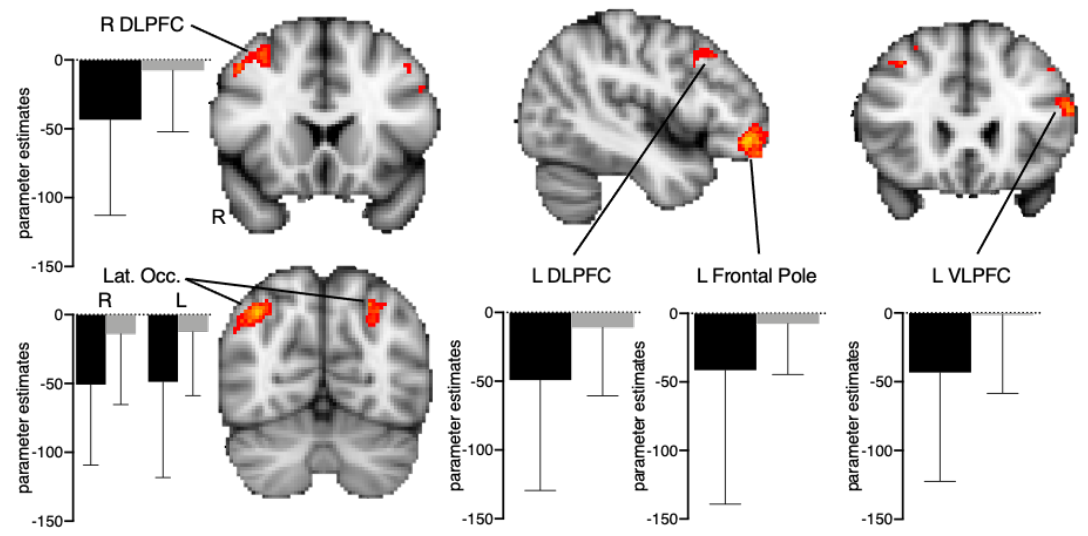

high heat

low heat

3.1

5.12
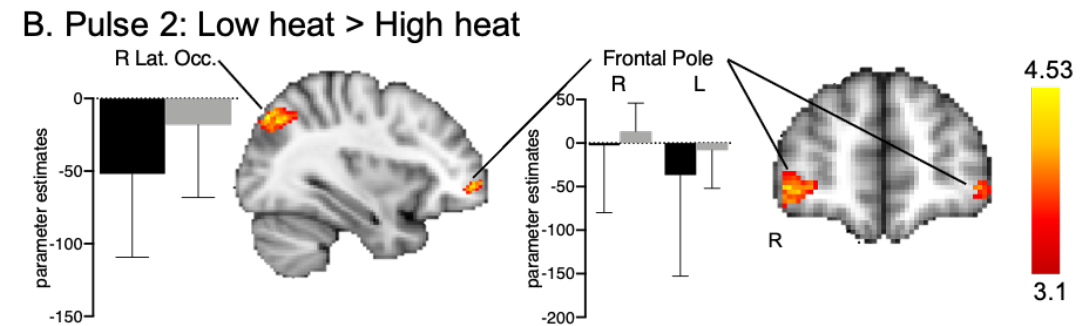

Figure 3. Neural responses during pain relief (low heat $>$ high heat). Regions seemingly more activated during the first (A.) and second (B.) pulse of low heat are nearly all driven by negative parameter estimates, or deactivations, indicating that pain relief does not actively engage regions such as the DLPFC or VLPFC, as shown in the activation maps (voxel-based threshold $z$ > 3.1, cluster correction of $p<0.05)$. L, left; R, right; DLPFC, dorsolateral prefrontal cortex; VLPFC, ventrolateral prefrontal cortex; Lat. Occ., lateral occipital cortex. 


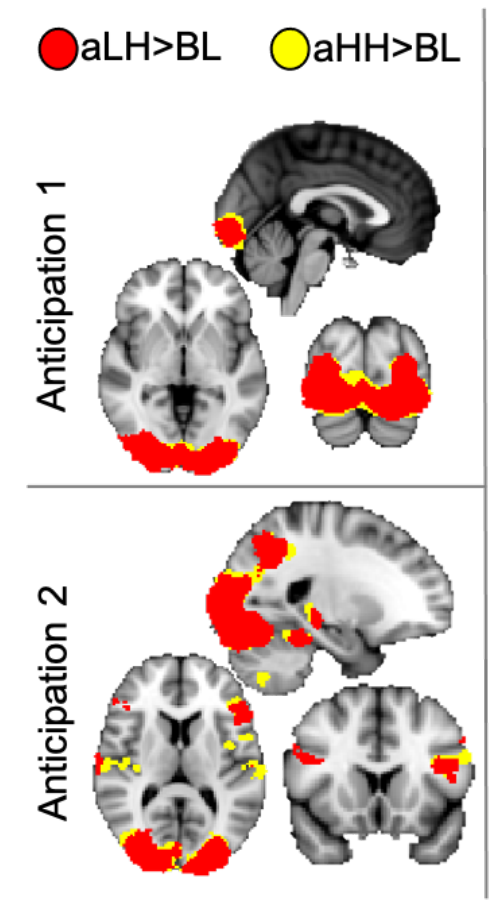

Anticipation 2:

ant. Low heat > ant. High heat

Figure 4. Anticipation-related activations. The left panel shows activations during the first and second period of anticipation (or expectation) of pain relief (low heat; red) and high heat (yellow) (voxel-based threshold $z>3.1$, cluster correction of $p<0.05$ ). The right panel shows significant differences within the occipital cortex in anticipation of low heat compared to high heat for only the second anticipation period, and only after decreasing the voxel-based threshold to $z>2.3$ (cluster correction of $p<0.05$ ). aHH, anticipation of high heat; aLH, anticipation of low heat; ant. anticipation; $R$, right. 


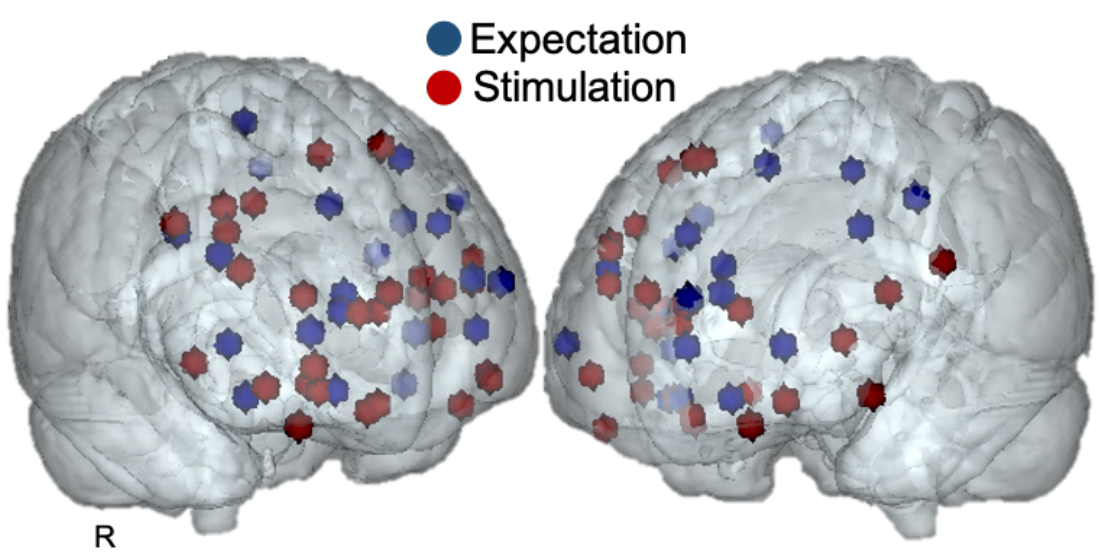

Figure 5. Localization of prefrontal cortex activations that have been reported during the expectation (blue) or stimulation (red) periods of placebo analgesia in studies conducted on healthy participants. Each sphere (rendered to $2 \mathrm{~mm}$ on an MNI 152 T1 standard template) represents the peak prefrontal cortex coordinates reported in the studies (see Table 3 for details and references). $R$, right. 